\title{
A COMPARISON OF THE EFFICIENCY OF THE BICYCLE WITH ANALOGOUS SYSTEMS IN NATURE
}

\author{
S. BURGESS, J. WANG \& R. VAIDYANATHAN \\ Department of Mechanical Engineering, Bristol University, UK.
}

\begin{abstract}
There are several analogies of mechanical design between the bicycle and nature. The coasting ability of a bicycle is analogous with the coasting ability of birds; the chain transmission has an analogy with the four-bar linkage in bird wings; the spoke-rim wheel layout has analogies with natural structures; and the tyre is analogous with some of the shock absorbing structures in animals. Comparing optimal design in the bicycle and nature demonstrates that the bicycle is very efficient as a transport machine and as a structure. However, one key difference with nature is that coasting animals like birds avoid steep gradients by flying on a level course or by using thermals to gain altitude. Analysis of the energy demands of cycling show that uphill cycling has a major negative impact on journey times and energy efficiency. Investing in dedicated cycle paths in order to avoid steep gradients could significantly increase the take-up of cycling and this would have significant long-term environmental advantages.
\end{abstract}

Keywords: bicycle, coasting, gradients, structural efficiency.

\section{INTRODUCTION}

It is estimated that there are over 600 million cars in the world [1]. These cars are a major source of energy consumption and pollution. It is estimated that there are over 1 billion bicycles in the world [1]. One of the best ways to reduce the number of car journeys and cars in the world is to encourage and facilitate increased use of the bicycle. Bicycles also have an important and positive social and economic impact for millions of people [2].

One way of encouraging use of the bicycle is to understand and publicise its efficiency compared to vehicles like cars. An effective way of understanding the efficiency of the bicycle is to compare it with analogous systems in nature. Natural systems can also indicate which aspects of the bicycle, and bicycle routes, have potential for greater efficiency. This article describes and analyses some of the most striking analogies between the bicycle and nature. The next section summarises the origin of the first efficient and practical bicycle design.

\section{ORIGIN OF THE FIRST EFFICIENT BICYCLE DESIGN}

One of the first efficient and practical bicycle layouts emerged in the latter part of the 1880s in the UK [3]. The bicycle (called a safety bicycle) is shown schematically in Fig. 1. The key features of the safety bicycle were:

- Two even sized wheels

- Rear driven wheel

- Chain and sprocket drive

- Pedals and crank drive

- Front steered wheel

- Tangential spokes in wheels

- Ball bearings in wheels and crank

These features are still key features of the modern bicycle. The only significant difference is the shape of the frame. Modern bicycles usually have a strengthening/stiffening cross member in the 

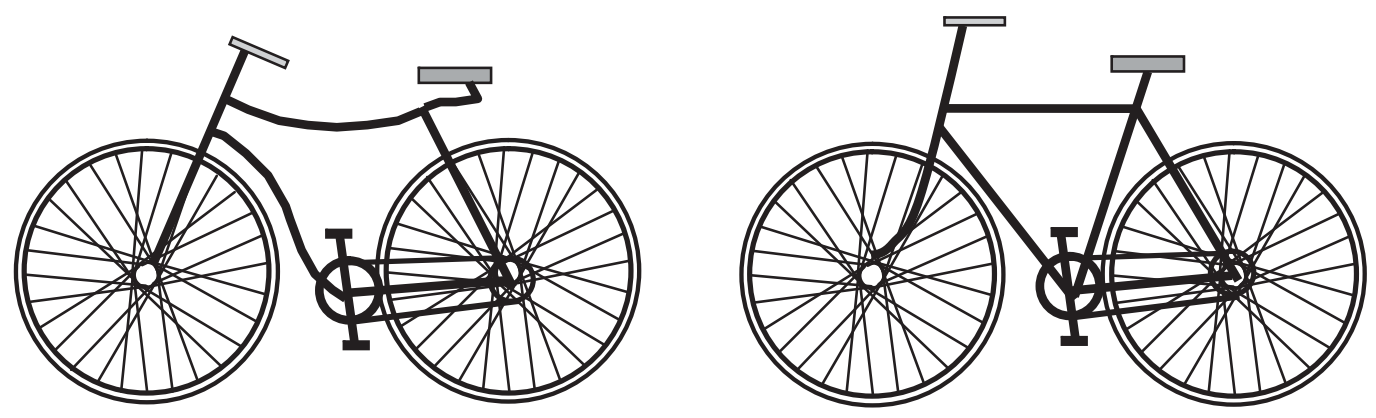

Figure 1: (a) The safety bicycle circa 1885. (b) The modern bicycle (tyres added circa 1888).

frame (turning the diamond frame into two triangles). Of course, the quality and performance of components has increased significantly over the last 120 years. However, it is remarkable how little the bicycle has changed in concept since the 1880s.

There were many types of cycle before the 1880s such as hobby horses, tricycles and penny farthings. However, none of these cycles were both efficient and safe to ride. For example, hobby horses could not be ridden continuously, tricycles were poor at cornering and penny farthings were inherently unstable and unsafe.

Many important elements of bicycle technology that contributed to the efficiency of the classic bicycle were developed just before the invention of the safety bicycle. Pedals and crank were invented in 1863 [3], steel ball bearings were invented in 1869 [3] and the bush roller chain was invented in 1880 [4]. Even though roller chains were used before 1880, the bush roller chain was the first chain to spread the load across the width of the pins in the chain and hence produce the high load capability required for the bicycle.

Some important elements of technology were developed during the 1880s such as the frame and the pneumatic tyre. The pneumatic tyre was invented around 1888 [3] and had a huge impact on the success of the safety bicycle, because it made cycling much more comfortable and protected the cycle from damaging impacts and vibrations.

There were other important elements of technology that appeared just after the emergence of the safety bicycle. In 1896, the two-speed hub was invented [3] making it easier for riders to cycle up hills. Another significant development was the invention of tarmac in 1902 that meant that it was easy to produce smooth road surfaces.

The safety bicycle concept was very quickly in demand by the general public. It is estimated that there were 1.5 million safety bicycles in the UK in 1895 [3]. The safety bicycle was so popular that by the early 1890 s the penny farthing was virtually obsolete. The quick commercial success of the safety bicycle concept shows that the safety bicycle had an effective and efficient design.

\section{COASTING IN THE BICYCLE AND NATURE}

One of the most important features of the bicycle is that it can coast along a smooth surface with relatively little resistance to motion. This is a great contrast with walking and running, which involves a complicated and energetic interaction with the ground. Whereas a bicycle will decelerate slowly from a given speed on level ground when drive torque is not applied, a person cannot keep moving in a useful way when walking or running is stopped.

Coasting is possible in the bicycle because of the low-resistance of the rolling motion of the wheels and bearings. The resistance to motion of the wheels and bearings is very small compared 
with the inertia of the bicycle and rider and so the momentum of the bicycle can keep it coasting for significant distances especially on level ground or downward slopes.

The ability to coast gives a cyclist the ability to do what birds and fish do in nature. Birds coast by gliding through the air (albeit with a slight loss of altitude) and fish coast by simply continuing along a level path through water. There are particular similarities between bird flight and cycling. At constant speed and level motion, both birds and cyclists are subject to air drag. The main difference is that whereas cycling involves rolling friction, birds must overcome induced drag to maintain altitude in the air.

The power requirements of bicycling and bird flight can be estimated with the equations shown in Table 1 . Birds are usually assumed to have two separate components of drag for body and wings.

The power requirements for a typical adult cyclist (and bike of average mass) and a typical medium-sized bird (black headed gull) are shown in Fig. 2. The results for a cyclist are similar to those found in reference [6] for a utility bike. The main difference between bird flight and cycling is that induced power is inversely proportional to speed whereas rolling resistance is proportional to speed. This means that whereas total power required increases exponentially with speed for cycling,

Table 1: Power equations for cycling and bird flight.

\begin{tabular}{llcc}
\hline & $\begin{array}{c}\text { Power to overcome air } \\
\text { drag (no wind) } \\
\text { (cycling [5], bird [6]) }\end{array}$ & $\begin{array}{c}\text { Power to overcome rolling } \\
\text { resistance [5] }\end{array}$ & $\begin{array}{c}\text { Power to overcome } \\
\text { induced drag [6] }\end{array}$ \\
\hline Cycling & $0.5 \rho \mathrm{C}_{\mathrm{d}} \mathrm{A}_{\mathrm{f}} \mathrm{V}^{3}$ & $\mathrm{~V}\left(\mathrm{~m}_{\text {rider }}+\mathrm{m}_{\text {bicycle }}\right) g \mu_{\mathrm{r}}$ & \\
Birds & $0.5 \rho \mathrm{C}_{\mathrm{d}} \mathrm{A}_{\mathrm{f}} \mathrm{V}^{3}$ (wings) & & $\frac{2 \mathrm{k} \mathrm{m}^{2} \mathrm{~g}^{2}}{\left(p \mathrm{~b}^{2} \mathrm{~V} \mathrm{r}\right)}$ \\
\hline
\end{tabular}

Where $\rho=$ air density $\left(\mathrm{m}^{3} / \mathrm{kg}\right), \mathrm{C}_{\mathrm{d}}=$ drag coefficient, $\mathrm{A}_{\mathrm{f}}=$ frontal area $\left(\mathrm{m}^{2}\right), \mathrm{V}=$ velocity $(\mathrm{m} / \mathrm{s})$, $\mathrm{m}=$ mass $(\mathrm{kg}), \mathrm{g}=$ gravitational constant $\left(\mathrm{m} / \mathrm{s}^{2}\right), \mu_{\mathrm{r}}=$ coefficient rolling friction, $\mathrm{k}=$ constant, $\mathrm{b}=$ wing $\operatorname{span}(\mathrm{m})$.
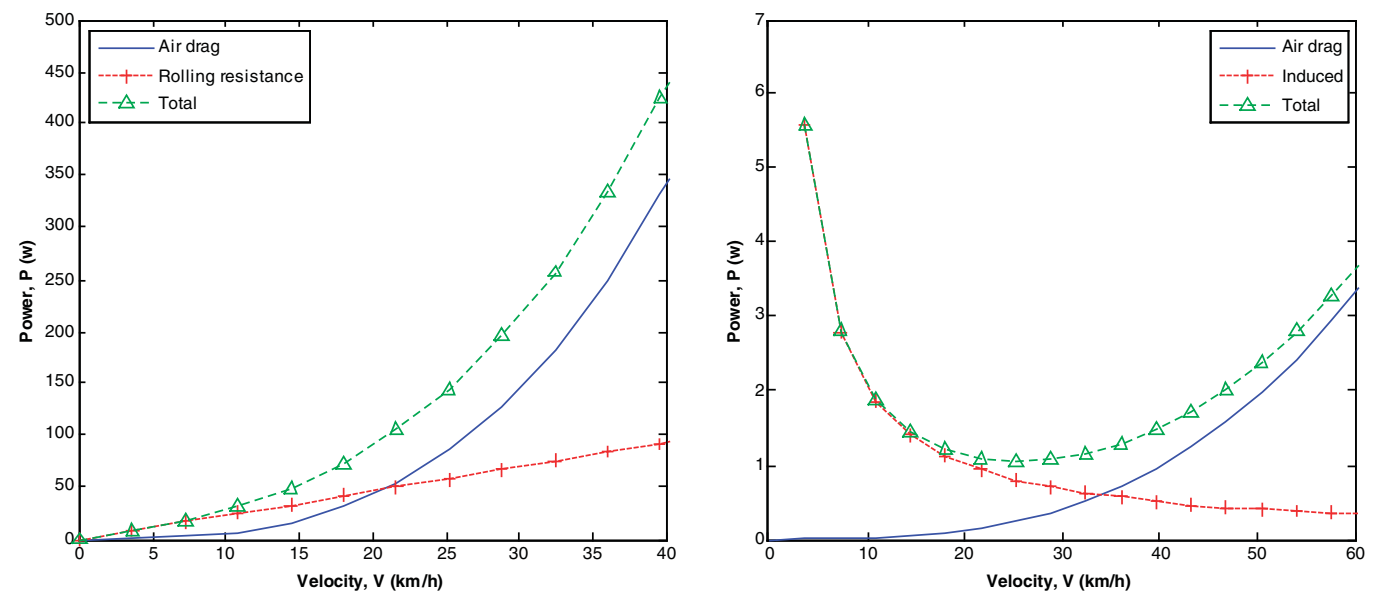

Figure 2: Power requirements for (a) cycling and (b) bird flight. 
the total power required for bird flight has a parabolic curve with minimal power achieved at some optimum velocity.

With bird flight there is a narrow range in which flight is efficient. In addition, large birds have difficulty in taking off and landing because flying at very low speeds requires huge energy. By contrast, cycling is very efficient at low speeds and it is relatively easy to start and stop. The efficiency and energetics of cycling compare well with bird flight with the two case studies in this article. Whereas the bird requires around $4.5 \mathrm{~W} / \mathrm{kg}$ at $20 \mathrm{~km} / \mathrm{h}$ the cyclist only requires around $1 \mathrm{~W} / \mathrm{kg}$ at $20 \mathrm{~km} / \mathrm{h}$.

Data for cycling: $\mathrm{m}_{\text {rider }}=75 \mathrm{~kg}, \mathrm{~m}_{\text {bicycle }}=10 \mathrm{~kg}, \mu_{\mathrm{r}}=0.01, \mathrm{C}_{\mathrm{d}}=1.0, \mathrm{~A}_{\mathrm{f}}=0.5 \mathrm{~m}^{2}$. Data for black headed gull: $\mathrm{m}=0.256 \mathrm{~kg}, \mathrm{C}_{\mathrm{d}}$ (wing) $=0.014, \mathrm{~A}_{\mathrm{f}}$ (wing) $=0.0884 \mathrm{~m}^{2}, \mathrm{C}_{\mathrm{d}}$ (body) $=0.2, \mathrm{~A}_{\mathrm{f}}($ body $)=0.001 \mathrm{~m}^{2}$, air density $=1 \mathrm{~kg} / \mathrm{m}^{3}, \mathrm{~g}=9.81 \mathrm{~kg} / \mathrm{m}^{2}, \mathrm{k}=1.2, \mathrm{~b}=0.93 \mathrm{~m}$. (Mass and sizes for the black headed gull are from Ref. [7], whereas the coefficients and other factors are from [6].)

\section{THE EFFECT OF INCLINES ON CYCLING EFFICIENCY}

The effect of an upward incline is the same for cyclists and birds. A term of $V m g \sin \theta$ is added to the power requirement equations where $\theta$ is the angle of ascent. The equation for the power requirement for the bicycle is now given by:a

$$
P=0.5 \rho C_{d} A_{f} V^{3}+V\left(m_{\text {rider }}+m_{\text {bicycle }}\right) g \cos \theta * \mu_{r}+V\left(m_{\text {rider }}+m_{\text {bicycle }}\right) g \sin \theta
$$

And the power equation for the bird is given by:

$$
P=0.5 \rho C_{d} A_{f} V^{3}(\text { wing })+0.5 \rho C_{d} A_{f} V^{3}(\text { body })+\frac{2 k^{2} g^{2}(\cos \theta)^{2}}{\pi b^{2} V \rho}+V m g \sin \theta
$$

Figure 3 shows the total power required for overcoming different ascent angles as a function of speed. The results show that the power required to overcome gravity is high, even for modest slopes. For both the bicycle and bird, there is a dramatic reduction of speed when power is kept constant.

The effect of a downward incline on cycling is illustrated in Fig. 4 which shows freewheeling speeds as a function of slope angle assuming the brakes are not being applied. The figure shows that freewheeling speeds are very high for significant slopes greater than 2 degrees. If a cyclist is limiting
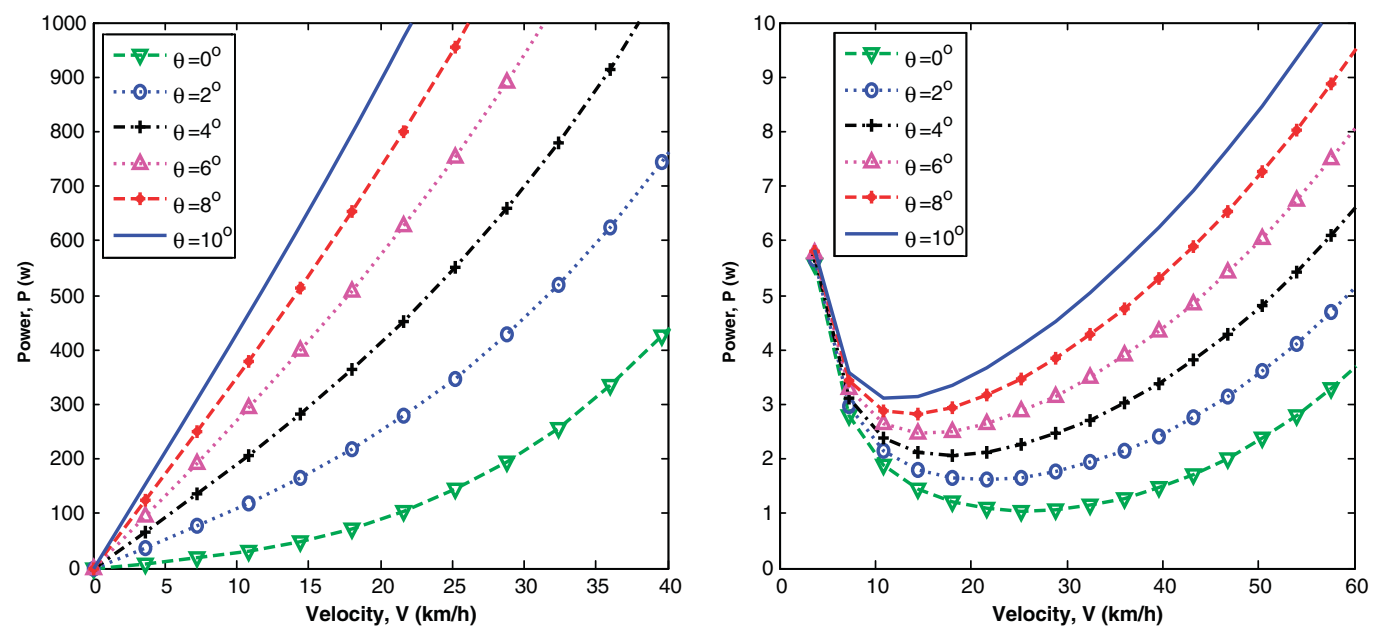

Figure 3: Effect of angle of ascent on power requirements for (a) cycling and (b) bird flight. 
speed to $6 \mathrm{~m} / \mathrm{s}$ ( $20 \mathrm{~km} /$ hour), then brakes need to be applied for slopes greater than around 1 degree for the bicycle considered in this article. Steep downward slopes lead to lost energy because the energy absorbed by the brakes is lost and cannot be put back into getting the bicycle back up a hill.

The effect of inclines for a typical journey in the UK is shown in Table 2. The table shows the typical distribution of gradients for a typical road route in the UK [8]. The table shows how much speed decreases for constant power for each of the upward slopes. The power is set at that required to achieve $6 \mathrm{~m} / \mathrm{s}$ on the flat in windless conditions.

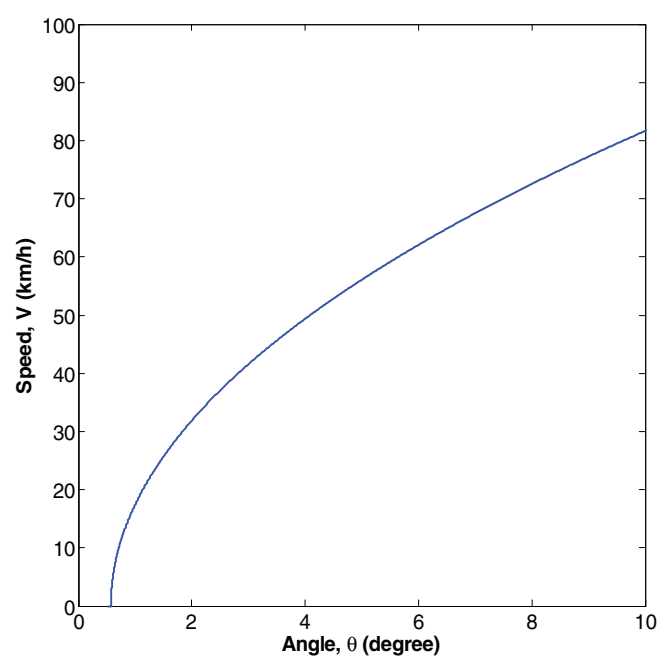

Figure 4: Freewheeling speed versus angle of descent.

Table 2: Gradients for a typical route in the UK [8].

\begin{tabular}{lcccc}
\hline $\begin{array}{l}\text { Gradient, } \theta \\
\text { (degrees) }\end{array}$ & $\begin{array}{c}\text { Relative distance, } \\
\mathrm{d}, \%\end{array}$ & $\begin{array}{c}\text { Speed, } \mathrm{V}, \mathrm{m} / \mathrm{s} \\
(\mathrm{P}=101 \mathrm{~W})\end{array}$ & $\begin{array}{c}\text { Relative time, } \mathrm{t} \\
\begin{array}{c}\text { Relive percentage } \\
\text { time, } \mathrm{t}^{\prime}, \%\end{array}\end{array}$ \\
\hline 10 uphill & 1.4 & 0.712 & 1.97 & 7.45 \\
8 uphill & 1.6 & 0.87 & 1.84 & 6.97 \\
6 uphill & 2 & 1.111 & 1.80 & 6.82 \\
4 uphill & 3 & 1.506 & 1.99 & 7.55 \\
2 uphill & 12 & 2.203 & 5.45 & 20.65 \\
0 & 60 & 6 & 10.00 & 37.91 \\
2 downhill & 12 & 6 & 2.00 & 7.58 \\
4 downhill & 3 & 6 & 0.50 & 1.90 \\
6 downhill & 2 & 6 & 0.33 & 1.26 \\
8 downhill & 1.6 & 6 & 0.27 & 1.01 \\
10 downhill & 1.4 & 6 & 0.23 & 0.88 \\
\hline
\end{tabular}


For the steepest slope of 10 degrees, the speed decreases to $0.712 \mathrm{~m} / \mathrm{s}$ which represents a reduction of around $800 \%$. Such a reduction is possible with modern gearing but the reduction of speed is frustrating for the cyclist because the speed is as slow as walking. The reduction in speed also results in a significant increase in journey time and decrease in efficiency because potential energy cannot be fully recouped going downhill.

The percentage relative time spent on each category of slope is given in the final column of Table 2. For example, even though the steepest slope is only $1.4 \%$ of the average journey in length, cyclists spend $7.5 \%$ of the time on this slope because of the constant power constraint. The journey time and energy demand for the distribution of slopes in Table 2 is $38 \%$ greater than for a flat route because speed is so slow on the uphill sections. If all hills were limited to 2 degrees, the slowest speed then becomes $2.2 \mathrm{~m} / \mathrm{s}$ which is much faster than speed for a 10 degree hill. Also, the journey time and energy demand is increased by only $26.7 \%$. Main-line railways typically have 0.6 degree maximum slopes (1 in 100). Therefore, limiting slopes to 2 degrees is not unfeasible.

Another approach to alleviate the problems of hills is to build energy storage devices that generate storable energy going down steep hills in order to give back that energy when going up hills. Flywheels do not have sufficient energy storage capacity to be of practical use. However, electromagnetic energy storage devices are feasible.

\section{OPTIMAL POSITIONING OF THE DRIVE SYSTEM}

A key feature of the classic bicycle layout is that the rider is positioned between the wheels. This is important for putting the centre of mass of the bicycle and rider comfortably between the two wheels and thus making it unlikely that the rider will tip over the front wheel after sharp braking or tip over the rear wheel on high acceleration. But positioning the rider between the wheels comes at a price. This position means that the riders torque cannot be directly applied at the wheel axle. Instead, it must be transferred from another position via a drive system.

The roller chain is ideal for transmitting torque because it is strong and stiff in tension but with virtually zero stiffness in bending. The friction in the chain occurs when the chain on the tension side articulates onto and off of the sprocket. When there are two sprockets of equal size (which is the case for certain gear ratios), the equation for transmission efficiency, $\eta$ is given by [9].

$$
\eta=1 \frac{2 \mu r_{p}}{R \sqrt{1+\mu^{2}}}
$$

where $\mu$ is the coefficient of friction between pin and bush, $r_{\mathrm{p}}$ is the radius of the pin and $R$ is the pitch radius of the sprocket. For a typical bicycle chain and sprocket layout the data are: $\mu=0.1$, $r_{\mathrm{p}}=1.8 \mathrm{~mm}, R=100 \mathrm{~mm}$ and the transmission efficiency is $99.64 \%$. The chain has high transmission efficiency because the pin radius is very small compared with the sprocket size. The highest efficiency is obtained by having larger sprockets which means there must be a trade-off between efficiency and mass [10].

The chain and sprocket system is analogous to a parallelogram four-bar linkage as shown in Fig. 5. Each time a new chain link articulates onto or off of the sprocket, it becomes the new pin in the four-bar linkage. This four-bar linkage gives the chain drive a polygonal action which means a slightly non-uniform velocity ratio between the two sprockets.

In nature, there is an analogy to the effective four-bar linkage of the chain drive. Birds have a parallelogram mechanism in the skeletal structure within their wing [11] in order to transmit torques from their shoulder joint to their elbow joint as shown in Fig. 6. This mechanism has the advantage of reducing the muscle mass in the wings and hence reducing power requirement for flapping the wings. 


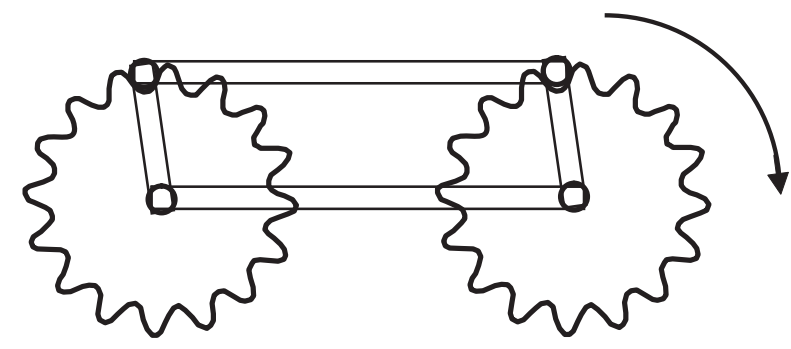

Figure 5: How the roller chain acts as a four-bar linkage.
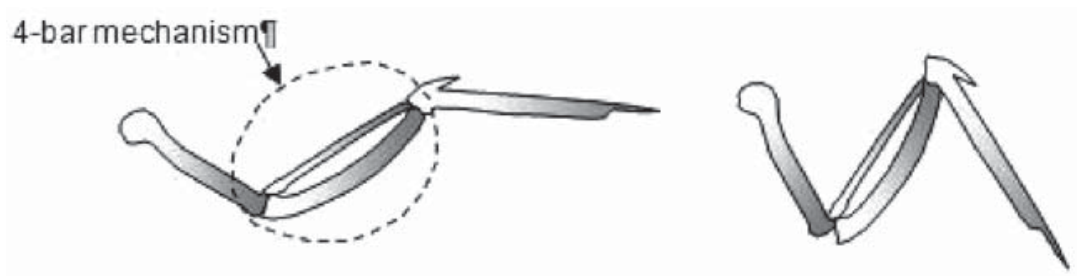

Figure 6: The four-bar linkage in a bird wing.

\section{STRUCTURAL EFFICIENCY OF THE BICYCLE WHEEL}

The bicycle wheel is a very efficient structure. A bicycle wheel can weigh as little as $0.7 \mathrm{~kg}$ and yet two wheels can take the weight of a rider weighing up to $100 \mathrm{~kg}$. The classic wheel layout shown in Fig. 7 has pre-tensioned spokes which are not radial but tangential to the hub. In addition, the spokes are not in the plane of the wheel but are wider apart at the hub than the rim of the wheel.

The spokes are pre-tensioned so that they are always in tension for all load cases. This is efficient because the spokes are much stronger in tension than compression. The spokes are tangential to the hub (as shown in Fig. 7) so that the wheel has strength and stiffness in torsion which is important when drive torques and braking torques are applied to the wheel. The spokes are out of plane so that the wheel can tolerate loads that are out of plane which can occur, for example, because pedal forces are not in line with the wheels.

One key reason for the efficiency of bicycle wheel is that the members are nearly perpendicular to each other (spokes are nearly perpendicular to the rim). This means that there is a minimisation of internally generated loads. By contrast, for a structure with triangular members, the loads in one member cause loads to be reacted in other members and this propagates throughout the structure.

The optimum structure for supporting a central load between two supports is a Michell structure [12] as shown in Fig. 8. The structure consists of a semi-circular compression rim with radial spokes in tension. Each radial spoke is perpendicular to the rim and so no internally generated loads exist in the structure. This is actually very similar to that of a bicycle wheel if the structure is duplicated with a mirror image of itself.

The total mass of the Michell truss is a function of the cross-sectional areas and lengths of the sections of the structure and the density of the material. So the mass function is given by:

$$
m=f(A, l, \rho)
$$




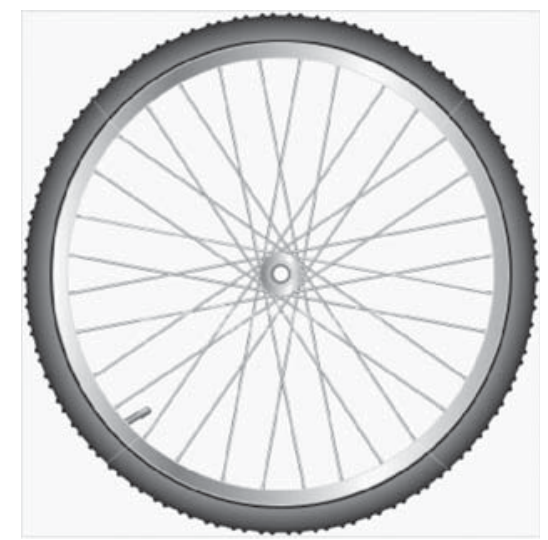

Figure 7: Bicycle wheel.

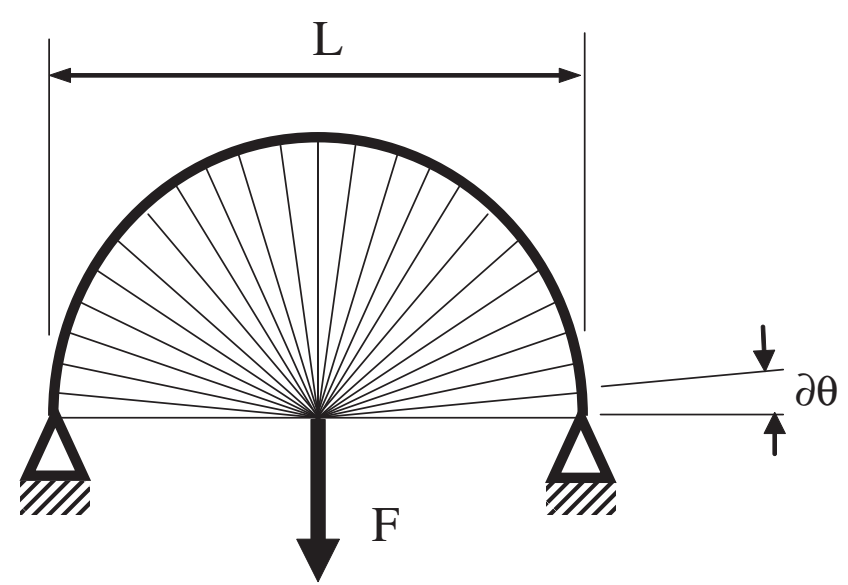

Figure 8: Michell truss for supporting a central load between two supports.

In the function, $A$ can be calculated from the forces and stresses with the equation:

$$
A=\frac{F}{\sigma}
$$

In the case of the bicycle wheel, the length of the individual compressive members of the structure is:

$$
l=\partial \theta \frac{\mathrm{L}}{2}
$$

And the length of the tension members is $L / 2$.

Therefore, the mass of the compression members of the Michell truss is given by:

$$
m_{c}=\Sigma \rho A_{c} \partial \theta \frac{L}{2}=\rho \frac{F}{\sigma} \frac{\pi L}{2} \frac{1}{2}
$$


where $A_{c}$ is the cross-sectional area of the compression members. The mass of the tension members of the Michell truss is given by:

$$
m_{t}=\sum \rho A_{t} \frac{L}{2}=\rho \frac{F}{\sigma} \frac{\pi L}{2} \frac{1}{2}
$$

where $A_{\mathrm{t}}$ is the cross-sectional area of the tension members. If the material has equal allowable stress in tension and compression, the total mass is given by:

$$
m_{\text {total }}=m_{c}+m_{t}=F \frac{\pi L}{2} \frac{\rho}{\sigma}
$$

where $\rho$ is the density and $\sigma_{\mathrm{y}}$ is the yield strength of the material. This Michell truss gives a very low mass compared with typical truss and beam structures for a centrally supported load [13, 14].

Equation (1) can be used to estimate the weight of an ideal bicycle wheel based on the Michell truss. Assuming a $0.7 \mathrm{~m}$ diameter wheel, a design load of $150 \mathrm{~kg}$ for one wheel, steel material of density $7,850 \mathrm{~kg} / \mathrm{m}^{3}$, an allowable stress of $100 \mathrm{MPa}$ and assuming a double Michell truss to make a whole wheel, eqn (1) gives a mass of around $0.25 \mathrm{~kg}$. This is an optimistic calculation because practical wheels have connecting components between the rim and the spokes and the spokes are tangentially aligned to the hub. In practice, racing wheels are as light as $500 \mathrm{~g}$ which is broadly consistent with the result of eqn (1) taking into account the extra components needed in a practical wheel such as spoke fasteners.

In nature, there are examples of structures with slender elements that are perpendicular and follow principal stresses. One example is the internal trabecular system of bone tissue aligns with the principal stresses in bones [15]. The spider's web also has near perpendicular members and resembles the Michell truss (although all its members are in tension and there are several concentric ring members).

Another analogy between the wheel and nature is the pre-stressing in the spokes. In nature, trees have pre-stressing in the outer layers of the trunk so that compressive stresses are minimised due to wind loading [16]. Spider's webs are also pre-stressed in tension so that when insects land on the web their weight does not cause the lower part of the web to collapse $[16,17]$.

Another analogy between the wheel and nature is the shock absorbing effect of the tyre. Many animals have layers of soft tissue in their limbs to absorb shock. The meniscus layer in the knee is an example of a shock absorbing layer. The elephant's foot has a special structure for acting as a shock absorber [18].

\section{ENVIRONMENTAL PERFORMANCE OF BICYCLES}

In nature, creatures generally transport themselves by self-propulsion. Some creatures like vultures make use of natural air movements like thermals to transport themselves. But generally creatures have highly optimised legs and wings for locomotion. Creatures that coast, like birds and fish, can travel large distances by self-propulsion. One of the best performances of self-locomotion is that of migrating birds across the Pacific Ocean. For example, a bar-tailed godwit is reported to have travelled 7,200 miles in 8 days across the Pacific without stopping [19]. This equates to an average distance of 900 miles (or 1,448 km) per day.

The bicycle enables humans to coast along the ground and travel significant distances by selfpropulsion. A bicycle weighing as little as $8 \mathrm{~kg}$ can support a $75 \mathrm{~kg}$ adult and carry them several hundred $\mathrm{km}$ in one day. The current bicycle record for distance covered in one day is $890 \mathrm{~km}$ set in 2008 [20]. This is over $60 \%$ of the average distance covered each day by the Godwit bird referenced above. The 24-h record for running is $303.5 \mathrm{~km}$ [21], and the 24-h record for walking is $226 \mathrm{~km}$ [21]. In terms of records, the bicycle enables a human to travel about three times further in one day compared 
Table 3: Record 24-h distances for different types of locomotion.

\begin{tabular}{lccc}
\hline Form of locomotion & Approximate body mass $(\mathrm{kg})$ & Record 24-h distance $(\mathrm{km})$ & Reference \\
\hline Bird flight & 0.5 & 1,448 & {$[19]$} \\
Cycling & 75 & 890 & {$[20]$} \\
Running & 75 & 303.5 & {$[21]$} \\
Walking & 75 & 226 & {$[21]$} \\
\hline
\end{tabular}

with running and about four times compared with walking (Table 3). Even a low cost bicycle with a non-athletic rider can easily transport a person $100 \mathrm{~km}$ in one day $(15 \mathrm{~km} /$ hour for 7 hours). Bicycles can be used not just to carry people but also to transport significant quantities of goods.

The environmental benefits of using a bicycle instead of a car are very significant. A typical bicycle weighs around $10 \mathrm{~kg}$ which is typically around 1/100 that of small car. There is an even greater difference in power requirements. Whereas a typical car requires the order of $50 \mathrm{KW}$ of power to drive, a typical bicycle requires the order of $50 \mathrm{~W}$ to propel. This is so small that selfpropulsion is quite easy for the rider. The reason for the larger difference in power than difference in mass is that cars go much faster than bicycles. A car also produces a significant amount of pollution during usage. As well as environmental benefits, cycling also has significant health benefits for the rider.

In Europe, there is great potential for increasing the use of the bicycle. For example, in the UK only $2 \%$ of journeys are taken by bicycle [22]. However, $41 \%$ of all trips are less than 2 miles [22]. A two mile trip is well within the capability of most cyclists and therefore there is great potential for increasing the use of the bicycle. Some European cities have up to $20 \%$ of journeys by bicycle [22] showing that change is possible.

\section{BARRIERS AND SOLUTIONS TO INCREASED BICYCLE USAGE}

The barriers to using cycling include: hills, safety, travel time, difficulty with luggage and culture. Climate conditions such as rain and cold weather can also be significant barriers to cycling [23]. The problem of hills and safety can be tackled by investing in dedicated cycle routes. In the same way that trains have dedicated flat routes, so cycles could have dedicated flat and safe routes where appropriate. Whilst this often involves high investment, the long-term environmental benefits can substantial. The World Health Organisation recommends pro-active policies to favour cycling such as the provision of dedicated cycle lanes on main roads [24].

Many countries are creating national cycle networks to actively encourage cycling. In 2002, the Taiwanese Sport Council launched the Planning and Establishment of a National Bikeway System in Taiwan [25]. The initial investment in this programme was the equivalent of around $£ 300$ million. The UK has a National Cycle Network that was opened in 1995 with an initial investment of $£ 43.5$ million from the Millennium Commission Lottery Grant [26]. At the end of December 2007, it had 12,000 miles of completed cycle paths and the network passes within 1 mile of half the population of the UK [26]. One-third of the network is on traffic-free paths and the other two-thirds follows quiet lanes or trafficcalmed roads. EuroVelo, the European cycle route network, is a project of the European Cyclists' Federation to develop 12 long-distance cycle routes crossing Europe. The total planned length is 60,000 $\mathrm{km}$ (37,282 miles), of which more than 44,000 km (27,340 miles) are in place as of April 2009 [27].

\section{CONCLUSIONS}

There are several analogies between optimal features in the bicycle and optimal features found in nature. The coasting ability of a bicycle is analogous with the coasting ability of birds; the 
chain transmission has an analogy with the four-bar linkage in the skeletal structure of bird wings; the spoke-rim wheel layout has analogies with natural web structures; and the tyre is analogous with some of the shock absorbing structures in animals. The numerous analogies should not be surprising because the bicycle is designed primarily for speed and efficiency and has been optimised for over 100 years. Many creatures are likewise optimised for speed and efficiency. The analogies between bicycle locomotion and animal locomotion identified in this article support the constructal law developed by Bejan to predict the locomotion of animals and vehicles [28].

Nature shows that the bicycle is well optimised and there are no obvious areas for making dramatic improvements of efficiency in the bicycle design itself. However, one key difference with nature is that coasting animals like birds avoid steep gradients by flying on a level course or by using thermals to gain altitude. Where a cycle route has hills, they significantly increase journey time and the energy demand. In the case study considered in this article, the hills in a typical cycle route in the UK increase journey time and energy demand by $37 \%$ assuming constant power. In addition, the speed of cycling is reduced by eight times on the steepest slopes. Investing in dedicated cycle paths in order to avoid steep gradients could encourage the take-up of cycling and this could have significant long-term environmental advantages.

\section{REFERENCES}

[1] Worldometer: http://www.worldometers.info/cars/.

[2] Pucher, J., Peng, Z.R., Mittal, N., Zhu, Y. \& Korattyswaroopam, N., Urban transport trends and policies in China and India: impacts of rapid economic growth. Transport Reviews, 27(4), pp. 379-410, July 2007.

[3] Woodforde, J., The Story of the Bicycle, Routledge \& Kegan Paul Ltd: London, 1970.

[4] Lodge, C., Theoretical and Experimental Studies of the Mechanical Behaviour of Roller Chains, PhD Thesis, Bristol University, 2002.

[5] Wilson, D.G. \& Whitt, F.R., Bicycling Science, MIT Press: Cambridge, 1982.

[6] Pennyquick, C.J., Modelling the Flying Bird, Elsevier Inc., 2008.

[7] Berg, C. \& Rayner, J., The moment of inertia of bird wings and the inertial power requirement for flapping flight. Journal of Experimental Biology, 198(8), pp. 1655-1664, 1995.

[8] Burgess, S.C., Stolarski, T.A. \& Karp, S., An accelerated life test for bicycle freewheels. Measurement Science and Technology (Institute of Physics), 1, pp. 1-8, 1990. doi:10.1088/0957-0233/1/1/001

[9] Lodge, C. \& Burgess, S.C., A model of the tension and transmission efficiency of a bush roller chain. Proceedings of the Institution of Mechanical Engineers, Part C: Journal of Mechanical Engineering Science, 216, pp. 385-394, 2002. doi:10.1243/0954406021525179

[10] Burgess, S.C., Improving cycling performance with large sprockets. Journal of the Engineering of Sport, 1(2), pp. 107-113, 1998. doi:10.1046/j.1460-2687.1999.00012.x

[11] Norberg, U.M., Vertebrate Flight, Springer-Verlag: Berlin, 1990.

[12] Michell, A.G.M., The limits of economy of material in frame-structures. Philosophical Magazine, 6(8), pp. 589-597, 1904.

[13] Burgess, S.C., The ranking of efficiency of structural layouts using form factors: part II: design for strength. Proceedings of the Institution of Mechanical Engineers, Part C: Journal of Mechanical Engineering Science, 212(2), pp. 129-140, 1998. doi:10.1243/0954406981521097

[14] Burgess, S.C., The ranking of efficiency of structural layouts using form factors: part I: design for stiffness. Proceedings of the Institution of Mechanical Engineers, Part C: Journal of MechanicalEngineering Science, 212(2), pp.117-128, 1998. doi:10.1243/0954406981521088, 
[15] Herrera, M., Panchon, A. \& Perez-Bacete, M., Trabecular trajectory in the articular processes of the human fourth cervical vertebra. Journal of Anatomy, 199(3), pp. 345-348, 2001. doi:10.1046/j.1469-7580.2001.19930345.x

[16] Vogel, S., Comparative Biomechanics, Princeton University Press, 2003.

[17] Papadopoulos, P., Sölter, J. \& Kremer, F., Hierarchies in the structural organization of spider silk-a quantitative model. Colloid and Polymer Science, 287(2), pp. 1435-1536, 2009.

[18] Weissengruber, G.E., Egger, G.F., Hutchinson, J.R., Groenewald, H.B., Elsässer, L., Famini, D. \& Forstenpointner, G., The structure of the cushions in the feet of African elephants. Journal of Anatomy, 209(6), pp. 781-792, 2006. doi:10.1111/j.1469-7580.2006.00648.x

[19] Gill Jr., R.E., Tibbitts, T.L., Douglas, D.C., Handel, C.M., Mulcahy, D.M., Gottschalck, J.C., Warnock, N., McCaffery, B.J., Battley, P.F. \& Piersma, T., Extreme endurance flights by landbirds crossing the Pacific Ocean: ecological corridor rather than barrier? Proceedings of the Royal Society B, 276, pp. 447-457, 2009. doi:10.1098/rspb.2008.1142

[20] http://www.ultracycling.com/records/24hourtrack_record2008.html.

[21] http://www.gbrathletics.com/wrec.htm.

[22] A sustainable future for cycling, Department of Transport Report, January 2008.

[23] Winters, M., Friesen, M.C., Koehoorn, M. \& Teschke, K., Utilitarian bicycling: a multilevel analysis of climate and personal influences. American Journal of Preventive Medicine, 32(1), pp. 52-58, 2007. doi:10.1016/j.amepre.2006.08.027

[24] Dora, C. \& Phillips, M. (eds), Transport, Environment and Health, WHO Regional Publications. European series 89, World Health Organisation, 2000.

[25] Chang, H.-W. \& Chang, H.-L., A strategic study of bicycle tourism in Taiwan. Journal of Eastern Asia Society for Transportation Studies, 5, pp. 1675-1677, October 2003.

[26] The National Cycle Network - Guidelines and Practical Details: Issue 2, 1997.

[27] The European cycle route network EuroVelo, A truly sustainable Trans-European Transport, Network (TEN-T), Response to the public consultation of the European Commission on the Green Paper in TEN-T, April 2009.

[28] Bejan, A. \& Marden, J.H., Unifying constructal theory for scale effects in running, swimming and flying. Journal of Experimental Biology, 209, pp. 238-248, 2006. doi:10.1242/jeb.01974 